\title{
Plastic Additives Decrease Agrin-Induced Acetylcholine Receptor Clusters and Myotube Formation in C2C12 Skeletal Muscle Cell Culture
}

\author{
Kelsey Neufeld, Kelly Ezell, Wade A. Grow \\ Department of Anatomy, Arizona College of Osteopathic Medicine, Midwestern University, Glendale, AZ, USA \\ Email: wgrowx@midwestern.edu
}

Received 5 March 2015; accepted 20 March 2015; published 23 March 2015

Copyright (C) 2015 by authors and Scientific Research Publishing Inc.

This work is licensed under the Creative Commons Attribution International License (CC BY).

http://creativecommons.org/licenses/by/4.0/

(c) (i) Dpen Access

\begin{abstract}
Common additives in plastics such as bisphenol A (BPA) or phthalates like di-(2-ethylhexyl) phthalate (DEHP) are environmental estrogens that have been shown to be endocrine disruptors in some experimental animal models. This project used the $\mathrm{C2C12}$ cell culture model to examine how exposure to BPA or DEHP affects two aspects of skeletal muscle development, the fusion of myoblasts into myotubes and agrin-induced clustering of acetylcholine receptors (AChRs). During myotube formation AChRs cluster spontaneously. Treatment with motor neuron derived agrin increases the frequency of AChR clusters through an agrin signaling pathway that also clusters other postsynaptic components of the neuromuscular synapse. For this project C2C12 cells were exposed to BPA or DEHP while myoblasts fused into myotubes. After exposure to $10 \mu \mathrm{M}$ BPA or 100 $\mu M$ DEHP the frequency of agrin-induced AChR clusters decreased. In addition, myotube formation decreased as a higher percentage of nuclei remained in myoblasts. Furthermore, BPA or DEHP reduced the amount of the myogenic regulatory factor myogenin. This suggests that BPA and DEHP decrease AChR clustering by reducing myogenin. Moreover, plastic additives like BPA and DEHP may pose a risk for skeletal muscle development in humans.
\end{abstract}

\section{Keywords}

AChR, Agrin, Bisphenol A (BPA), C2C12, Di-(2-Ethylhexyl) Phthalate (DEHP), Myogenin

\section{Introduction}

During development of the neuromuscular synapse both the concentration and location of acetylcholine recep-

How to cite this paper: Neufeld, K., Ezell, K. and Grow, W.A. (2015) Plastic Additives Decrease Agrin-Induced Acetylcholine Receptor Clusters and Myotube Formation in C2C12 Skeletal Muscle Cell Culture. CellBio, 4, 12-22.

http://dx.doi.org/10.4236/cellbio.2015.41002 
tors (AChRs) on the muscle cell surface are regulated [1], resulting in a mature neuromuscular synapse with a concentration of AChRs that is 1000 times as great as that found extrasynaptically [2]. AChRs aggregate and co-localize with a large number of other molecules [3]-[5], including a muscle specific kinase (MuSK). In development MuSK is essential for the signaling events of neuromuscular synapse formation [6]-[9], and in the adult is found only at neuromuscular synapses [10]. Aggregation of AChRs and other molecules results in a postsynaptic scaffold which provides the framework for the muscle fiber contribution at the neuromuscular synapse, serves to stabilize the junction between nerve and muscle, and focuses the motor neuron terminal release of the neurotransmitter acetylcholine. AChRs bind this neurotransmitter, which initiates a sequence of intracellular events, with the end result being contraction of the mature muscle fiber. The formation of this postsynaptic scaffold is driven by agrin released from motor neurons [11]-[15].

Skeletal muscle cell cultures, such as the C2C12 cell line derived from mouse hindlimb, provide simplified systems for studying development of the postsynaptic component of the neuromuscular synapse [16] [17]. Cultured myotubes cluster AChRs spontaneously and respond to agrin application with an increase in the frequency of AChR clusters [18]-[20]. Agrin exists in multiple isoforms, with the agrin $_{4,8}$ isoform found exclusively in neural tissue and able to cluster AChRs to a much greater extent than other isoforms [21]. There is a specific requirement for neural agrin to tyrosine phosphorylate both MuSK [8] and the AChR $\beta$ subunit [22] [23], signal transduction events which precede AChR cluster formation. In addition, the myogenic regulatory factor myogenin activates genes for AChR subunits [24] [25]. This suggests that myogenic regulatory factors like myogenin are intricately linked to the development of the postsynaptic component of the neuromuscular synapse.

BisphenolA (BPA) is a plastic additive that is made by combining acetone and phenol and is a key component of polycarbonate plastic and epoxy resins. Common products that contain polycarbonate plastic include baby bottles, water bottles, sports equipment, medical devices, dental fillings, CDs and DVDs. Epoxy resins are found lining food and beverage cans. Di-(2-ethylhexyl) phthalate (DEHP) is a member of a family of plastic softeners called phthalates that are added to polyvinyl chlorides to make them more pliable. Phthalates are rather ubiquitous, found in flexible plastics such as children's chew toys, adult sex toys, medical tubing, shower curtains, and car interiors. In recent years there has been an increased awareness and concern regarding the use of plastic additives. BPA and phthalates are endocrine disruptors to which infants and pregnant women are routinely exposed, with dramatic increases in exposure for patients with specific medical conditions. A comprehensive review of plastic additives can be found in Mark Schapiro's book "Exposed" [26].

Previously we demonstrated that another endocrine disruptor, the pesticide methoxychlor, decreases myotube formation by slowing myoblast proliferation [27]. The objective of the current study was to investigate whether plastic additives interfere with agrin-induced AChR clustering and myotube formation. The C2C12 cell culture model has proven useful for asking fundamental questions concerned with muscle development and neuromuscular synapse formation, and is ideal for examining how plastic additives might interfere with these developmental events.

\section{Materials and Methods}

\subsection{Cell Culture Maintenance}

C2C12 myoblasts were derived from mouse hind limb [16] [17], and are commonly used for skeletal muscle cell culture experiments. They are ideal for studying myoblast fusion to form myotubes, and acetylcholine receptor (AChR) clustering. For normal maintenance of C2C12 cell culture, myoblasts were first plated in growth medium (GM) on $10 \mathrm{~cm}$ plates at approximately 20\% confluence. GM consists of Dulbecco's modified Eagle's medium (DMEM) plus 20\% fetal bovine serum, $0.5 \%$ chick embryo extract and $100 \mathrm{U} / \mathrm{ml}$ penicillin. Fresh GM was added daily, and myoblast cultures were split into new plates at approximately $60 \%$ confluence. For formation of myotubes, myoblasts were plated in GM on $22 \times 22 \mathrm{~mm}$ cover slips that had been flamed in 200-proof ethanol and placed in 6-well plates. Fresh GM was added daily. After 48 hours in GM, myoblast cultures typically reached $80 \%$ confluence, and cultures were then switched to differentiation medium (DM). DM consists of DMEM plus 2\% horse serum and $100 \mathrm{U} / \mathrm{ml}$ penicillin. Fresh DM was added daily as myoblasts fused to form myotubes, and cultures were maintained for 72 hours in DM. All cultures were exposed to $10 \mathrm{ng} / \mathrm{ml}$ agrin (R \& D Systems) for the last 16 hours of 72 hours in DM to induce AChR clustering. Some cultures were exposed to $10 \mathrm{nM}-10 \mu \mathrm{M}$ bisphenol A (BPA; Sigma-Aldrich) or $10 \mathrm{nM}-100 \mu \mathrm{M}$ di-(2-ethylhexyl) phthalate (DEHP; Sigma-Aldrich) for the last 48 hours of 72 hours in DM. BPA stock solution was created by dissolving BPA in 
dimethyl sulfoxide (DMSO; Sigma-Aldrich), while DEHP was purchased as a stock solution in DMSO. Serial dilutions of stock solutions with DM achieved the treatment concentrations. The highest concentration of DMSO the cells were exposed to has previously been shown to have no effect on myoblast proliferation or fusion into myotubes [28]. The incubator was maintained at $37^{\circ} \mathrm{C}$ under $8 \%$ carbon dioxide and $100 \%$ humidity.

\subsection{Acetylcholine Receptor Clustering Assay}

AChRs were labeled by the binding of $\alpha$-bungarotoxin conjugated to tetramethylrhodamine (Molecular Probes) [29]. Cultures were incubated in the toxin-containing medium for 30 minutes at $37^{\circ} \mathrm{C}$ to label AChRs after 72 hours in DM. The cover slips were rinsed three times with room temperature phosphate buffered saline (PBS), fixed for 10 minutes with $2 \%$ paraformaldehyde in PBS, rinsed three times with PBS, dehydrated in cold methanol for 5 minutes at $-20^{\circ} \mathrm{C}$, and mounted on microscope slides in Vectashield Mounting Medium for Fluorescence (Vector Laboratories). For some experiments the mounting medium contained 4'6-diamidino-2-phenylindole (DAPI) to visualize nuclei. AChR clusters were visualized with an IX70 Olympus inverted microscope under the 20× objective (yielding a total magnification of 200×), and fluorescent images were captured as high-resolution JPG files with an Olympus camera with Magnafire digital imaging software. Bright clusters of AChRs were observed on all aspects of myotubes in fluorescent images. AChR clusters were counted from 25 images captured as JPG files from each cover slip. One cover slip was analyzed for each treatment group or control in each of five replicate experiments. AChR clusters were counted by an individual blind to treatment group. These data were utilized to assay agrin-induced AChR clustering in untreated cultures, or after exposure to $10 \mathrm{nM}-10 \mu \mathrm{M}$ BPA or $10 \mathrm{nM}-100 \mu \mathrm{M}$ DEHP for the last 48 hours of 72 hours in DM. Comparisons of untreated cultures with cultures exposed to BPA or DEHP were analyzed by Student's t-test to determine statistically different results at $\mathrm{p}<0.05$. Representative images were assembled into Figure 3 using Adobe Photoshop.

\subsection{Myotube Formation Index}

Cell cultures were visualized with an IX70 Olympus inverted microscope under the 20× objective (yielding a total magnification of 200×), and representative phase contrast and DAPI images were captured as high-resolution JPG files with an Olympus camera with Magnafire digital imaging software. These JPG files were utilized to quantify myotube formation by modifying a myoblast fusion index paradigm [30] into a myotube formation index used in our laboratory [27] [31] [32]. In brief, the number of nuclei in myoblasts (defined as cells with one or two nuclei) and myotubes (defined as cells with three or more nuclei) were counted after 72 hours in DM. Only nuclei obviously in myoblasts were counted as such. All nuclei for which a designation was difficult were grouped with the nuclei in myotubes. This method biased the data toward a greater percentage of nuclei in myotubes. A total of ten pairs of images (phase contrast and DAPI) were analyzed for untreated cultures, five pairs of images for cultures exposed to $10 \mu \mathrm{M}$ BPA for the last 48 hours of 72 hours in DM, and five pairs of images for cultures exposed to $100 \mu \mathrm{M}$ DEHP for the last 48 hours of 72 hours in DM. For each image, nuclei were determined to be either in a myoblast or myotube prior to counting. The myotube formation index was then calculated as nuclei in myoblasts divided by total nuclei in the image and reported in Table 1 as a percentage of nuclei in myoblasts.

\subsection{Western Blots}

To assay for protein levels of the myogenic regulatory factor myogenin, myotube cultures were divided into untreated cultures, those that had been exposed to $10 \mu \mathrm{M}$ or $100 \mu \mathrm{M}$ BPA for the last 48 hours of 72 hours in DM, and those that had been exposed to $100 \mu \mathrm{M}$ or $1 \mathrm{mM}$ DEHP for the last 48 hours of 72 hours in DM. Myotubecultures were rinsed twice with calcium- and magnesium-free PBS (CMF-PBS), scraped off in RIPA complete lysis buffer (containing PMSF, sodium orthovanadate, and protease inhibitors), agitated for 30 minutes on ice, and then centrifuged at 13,000 g for 2 minutes to create pellets containing insoluble materials such as organelles and extracellular matrix. The extracted supernatant was then frozen. At a later time samples were thawed, a BCA protein assay was performed to determine the concentration of protein in each sample, and samples were boiled for 5 minutes in sample buffer to reduce and denature proteins. Then samples were separated by electrophoresis on a $10 \%$ polyacrylamide gel (Bio-Rad) and transferred to a nitrocellulose membrane. The membranes were blocked with $5 \%$ milk in TBS-T, probed for 16 hours at $4^{\circ} \mathrm{C}$ with a mouse monoclonal antibody to myoge- 
Table 1. BPA or DEHP decrease myotube formation. The myotube formation index was calculated as nuclei in myoblasts divided by total nuclei and reported as a percentage of nuclei in myoblasts. The larger the percentage of nuclei remaining in myoblasts, the less myotube formation has proceeded. Myotube formation was decreased with exposure to $10 \mu \mathrm{M}$ BPA or $100 \mu \mathrm{M}$ DEHP for the last 48 hours of 72 hours in differentiation medium.

\begin{tabular}{ccccc}
\hline & $\begin{array}{c}\text { Nuclei in } \\
\text { Myoblasts }\end{array}$ & $\begin{array}{c}\text { Nuclei in } \\
\text { Myotubes }\end{array}$ & Total Nuclei & $\begin{array}{c}\text { \% Nuclei in } \\
\text { Myoblasts }\end{array}$ \\
\hline Untreated & 92 & 1553 & 1645 & $5.9 \%$ \\
BPA $10 \mu \mathrm{M}$ & 181 & 1017 & 1198 & $17.8 \%$ \\
Untreated & 112 & 1571 & 1683 & $7.1 \%$ \\
DEHP $100 \mu \mathrm{M}$ & 202 & 1067 & 1269 & $18.9 \%$ \\
\hline
\end{tabular}

nin (sc-12732; Santa Cruz Biotechnology) at 1:1000 in blocking solution, and then probed by a goat anti-mouse secondary antibody (92-32210; Li-Cor) at 1:10,000 in blocking solution for 30 minutes. The resultant western blot was then visualized with the Odyssey CLx, a near infrared imaging system. It uses solid state diode lasers to excite at 685 and $785 \mathrm{~nm}$. For scanning, the western blot was placed on the glass surface of the odyssey and covered with a rubber mat. In the Li-Cor software a box was created to define the scanning area of the blot. The 700 and 800 channels were chosen and low quality image quality and $169 \mu \mathrm{m}$ resolution was checked before "start scan" was pressed. As a loading control, all samples were also probed with a mouse monoclonal antibody to actin (sc-8432; Santa Cruz Biotechnology).

\section{Results}

The results reported here demonstrate that $10 \mu \mathrm{M}$ BPA or $100 \mu \mathrm{M}$ DEHP decreased the frequency of agrin-induced AChR clusters and myotube formation. Furthermore, BPA or DEHP reduced the amount of myogenin protein.

\subsection{BPA or DEHP Decrease the Frequency of Agrin-Induced AChR Clusters}

AChRs cluster spontaneously with a baseline frequency on C2C12 myotubes and this clustering is increased with agrin treatment [18]-[20]. C2C12 cell cultures were switched from GM to DM at 80\% confluence, $10 \mathrm{ng} / \mathrm{ml}$ agrin was added for the last 16 hours in DM, and myotubes were examined for AChR clustering after 72 hours in DM. Some cultures were left untreated (control cultures), while others were exposed to $10 \mathrm{nM}-10 \mu \mathrm{M}$ BPA or $10 \mathrm{nM}-100 \mu \mathrm{M}$ DEHP for the last 48 hours of 72 hours in DM. For each experiment one cover slip was analyzed for each treatment group or control. AChR clusters were counted from 25 images captured as JPG files from each cover slip. Each experiment was replicated five times with similar results, with typical data sets reported (Figure 1 and Figure 2). $10 \mu \mathrm{M}$ BPA (Figure 1 and Figure 3) or $100 \mu \mathrm{M}$ DEHP (Figure 2 and Figure 3) was sufficient to decrease the frequency of agrin-induced AChR clusters, with statistical significance at p $<0.05$ using Student's t-test. Specifically $10 \mu \mathrm{M}$ BPA decreased agrin-induced AChR clusters by $30 \%$, while $100 \mu \mathrm{M}$ DEHP decreased agrin-induced AChR clusters by 38\%, in the data sets reported.

\subsection{BPA or DEHP Decrease Myotube Formation}

Myotube formation was quantified by modifying a myoblast fusion index paradigm [30] into a myotube formation index used in our laboratory [27] [31] [32]. In brief, the number of nuclei in myoblasts (defined as cells with one or two nuclei) and myotubes (defined as cells with three or more nuclei) were counted after 72 hours in DM. The myotube formation index was then calculated as nuclei in myoblasts divided by total nuclei in the image and reported as a percentage of nuclei in myoblasts (Table 1). The larger the percentage of nuclei remaining in myoblasts, the less myotube formation has proceeded. The percentage of nuclei in myoblasts more than doubled with exposure to $10 \mu \mathrm{M}$ BPA or $100 \mu \mathrm{M}$ DEHP.

\subsection{BPA or DEHP Reduce Myogenin Protein}

A decrease in the frequency of agrin-induced AChR clusters could have many causes. The myogenic regulatory factor myogenin activates genes for AChR subunits [24] [25]. This suggests that myogenic regulatory factors 


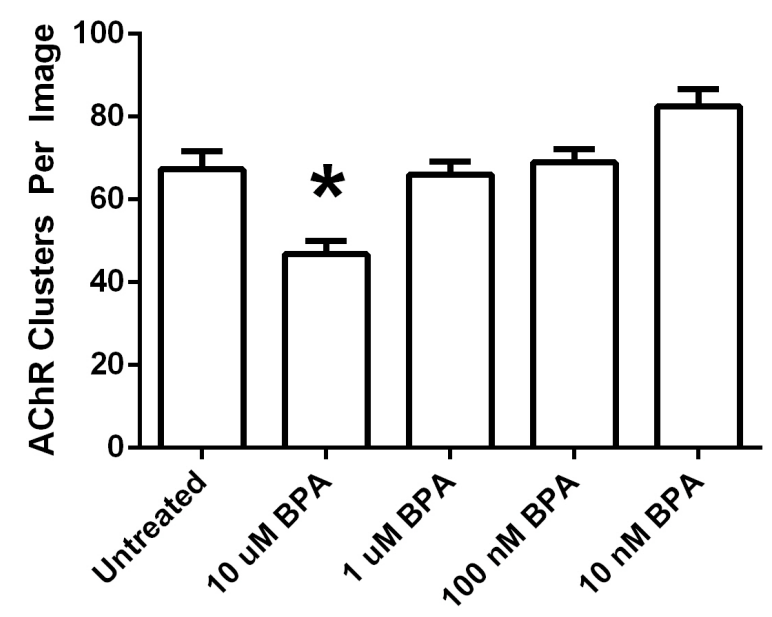

Figure 1. BPA decreases the frequency of agrin-induced AChR clusters. Frequency of agrin-induced AChR clusters were quantified by analyzing fluorescent images from agrininduced cultures that were untreated or were exposed to 10 $\mathrm{nM}-10 \mu \mathrm{M}$ BPA for the last 48 hours of 72 hours in differentiation medium. The histogram reveals that exposure to $10 \mu \mathrm{M}$ BPA was sufficient to decrease agrin-induced AChR clusters relative to untreated cultures, using Student's t-test at $\mathrm{p}<0.05$. (*) statistically decreased from untreated cultures.

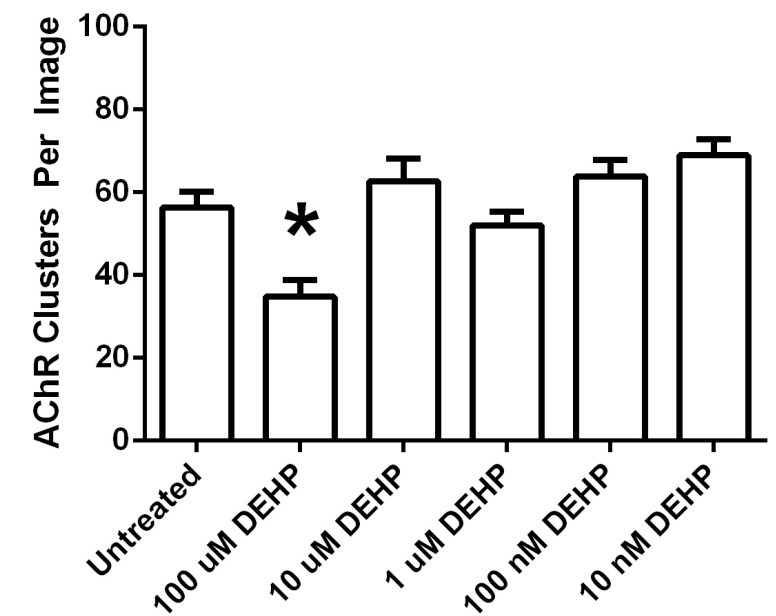

Figure 2. DEHP decreases the frequency of agrin-induced AChR clusters. Frequency of agrin-induced AChR clusters were quantified by analyzing fluorescent images from agrininduced cultures that were untreated or were exposed to 10 $\mathrm{nM}-100 \mu \mathrm{M}$ DEHP for the last 48 hours of 72 hours in differentiation medium. The histogram reveals that exposure to $100 \mu \mathrm{M}$ DEHP was sufficient to decrease agrin-induced AChR clusters relative to untreated cultures, using Student's t-test at $\mathrm{p}<0.05$. (*) statistically decreased from untreated cultures.

like myogenin are intricately linked to the development of the postsynaptic component of the neuromuscular synapse. Western blots were used to measure the amount of myogenin protein. C2C12 cell cultures were exposed to $10 \mu \mathrm{M}$ or $100 \mu \mathrm{M}$ BPA, or $100 \mu \mathrm{M}$ or $1 \mathrm{mM}$ DEHP, for the last 48 hours of 72 hours in DM. Each experiment was replicated three times with similar results, with typical western blots reported (Figure 4 and 

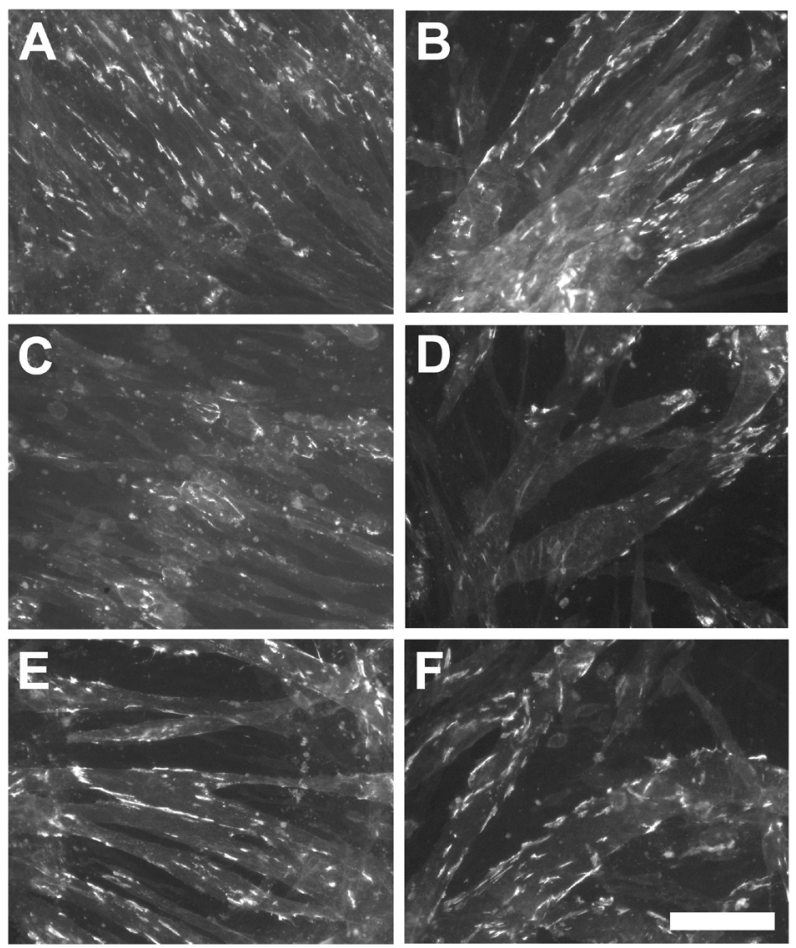

Figure 3. Examples of cell cultures exposed to BPA or DEHP. Fluorescent images were captured from agrin-induced cultures that were untreated (A) (B), or exposed for the last 48 hours of 72 hours in differentiation medium to $10 \mu \mathrm{M}$ BPA (C), $1 \mu \mathrm{M}$ BPA (E), $100 \mu \mathrm{M}$ DEHP (D), or $10 \mu \mathrm{M}$ DEHP (F). Fluorescent areas are clusters of AChRs. Scale bar $=100 \mu \mathrm{m}$.

Figure 5). $10 \mu \mathrm{M}$ or $100 \mu \mathrm{M}$ BPA (Figure 4), or $100 \mu \mathrm{M}$ or $1 \mathrm{mM}$ DEHP (Figure 5), reduced the amount of myogenin protein. Specifically $10 \mu \mathrm{M}$ or $100 \mu \mathrm{M}$ BPA reduced myogenin to $77 \%$ of the amount in untreated cultures, while $100 \mu \mathrm{M}$ DEHP reduced myogenin to $54 \%$ and $1 \mathrm{mM}$ DEHP reduced myogenin to $28 \%$, in the western blots reported. All values compared were a ratio of myogenin to actin and normalized to 1.00 for untreated cultures, as analyzed by the Li-Cor software.

\section{Discussion}

BPA and its metabolites have been detected in human urine, breast milk, saliva, serum, plasma, ovarian follicular fluid, and amniotic fluid [33]. Some of the earliest studies to investigate BPA were concerned with exposure from resin-based composites and sealants used in dentistry. Samples collected one hour after treatment with a dental sealant based on BPA yielded 90 - $931 \mu \mathrm{g}$ of BPA in the patient's saliva. In addition, the estrogenicity of BPA was demonstrated in a breast cancer cell culture system [34]. However, based on an analysis of several studies of BPA levels in food and drink, as well as human urine, it was estimated that more typically exposure to BPA ranges from about 0.001 to $0.1 \mu \mathrm{g} / \mathrm{kg} /$ day [35]. By the backward calculation approach based on urinary excretion, 95\% confidence intervals for daily intake of BPA for high-exposure populations in Japan yielded 0.037 - $0.064 \mu \mathrm{g} / \mathrm{kg} /$ day for males and 0.043 to $0.075 \mu \mathrm{g} / \mathrm{kg} /$ day for females [36]. Even a study of infants fed baby formula found a probable maximum daily intake of BPA of only $1.35 \mu \mathrm{g} / \mathrm{kg} / \mathrm{day}$, with the amount of BPA detected in various liquid infant formulas ranging from $2.27 \mathrm{ng} / \mathrm{g}$ to $10.2 \mathrm{ng} / \mathrm{g}$ [37]. In summary, it is likely that daily intake of BPA for most humans is less than $1 \mu \mathrm{g} / \mathrm{kg} /$ day [38]. For comparison, the United States Environmental Protection Agency reference dose for BPA is $50 \mu \mathrm{g} / \mathrm{kg} /$ day, the European Union temporary tolerable daily intake of BPA is $10 \mu \mathrm{g} / \mathrm{kg} /$ day [36], and the provisional tolerable daily intake of BPA established by Health Canada is $25 \mu \mathrm{g} / \mathrm{kg} / \mathrm{day}$ [37]. Because BPA is metabolized and eliminated in urine rather quickly, a number of studies have concluded that it is unlikely that humans, including infants and children, are at risk from 


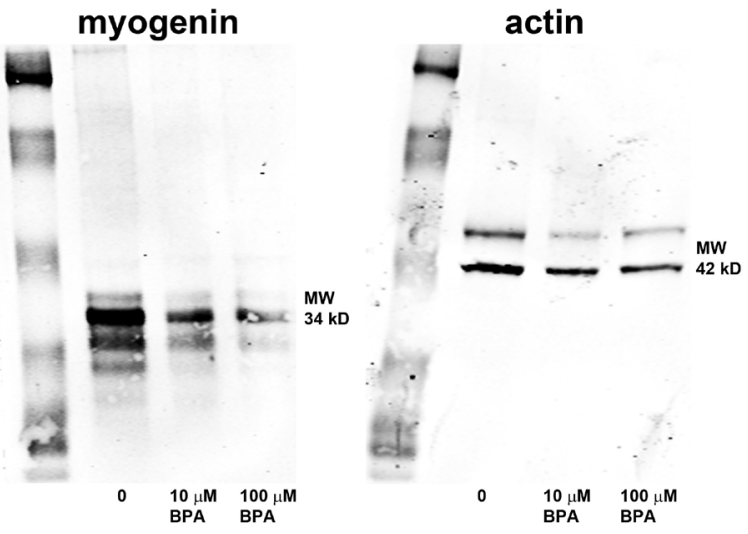

Figure 4. BPA reduces myogenin protein. Untreated agrininduced cultures were compared with cultures exposed to 10 $\mu \mathrm{M}$ or $100 \mu \mathrm{M}$ BPA for the last 48 hours of 72 hours in differentiation medium. Cultures were assayed for the amount of myogenin protein. BPA at concentrations that decreased the frequency of AChR clusters also decreased the amount of myogenin protein.

myogenin

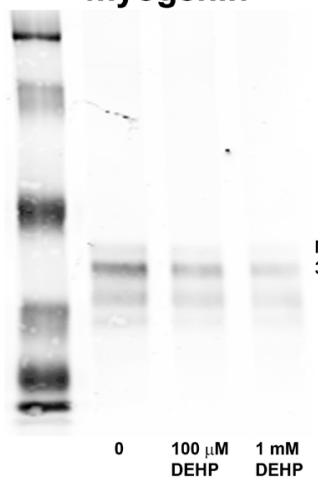

actin

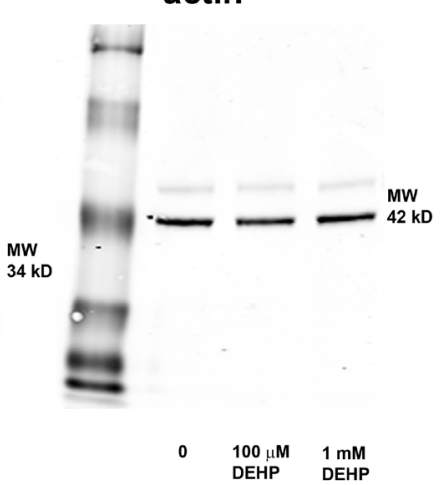

Figure 5. DEHP reduces myogenin protein. Untreated agrininduced cultures were compared with cultures exposed to 100 $\mu \mathrm{M}$ or $1 \mathrm{mM}$ DEHP for the last 48 hours of 72 hours in differentiation medium. Cultures were assayed for the amount of myogenin protein. DEHP at concentrations that decreased the frequency of AChR clusters also decreased the amount of myogenin protein.

the presence of BPA in consumer products [35] [36]. The human data differs from animal data suggesting that BPA is acutely toxic to aquatic organisms [38] and that low doses of BPA have estrogenic effects in laboratory animals [35].

Phthalates, including DEHP or its primary metabolite mono-2-ethylhexyl phthalate (MEHP), are commonly measured in urine, serum, or breast milk. When DEHP or MEHP was measured in the serum of cord blood of newborns, a correlation between higher phthalate concentrations and shorter pregnancy duration was found [39]. In a study conducted 1 - 3 months postnatally, breast milk samples were collected from mothers and serum samples from their male infants. The breast milk contained several phthalates including MEHP with a median value of $11 \mu \mathrm{g} / \mathrm{L}$ and a range of $1.5-1410 \mu \mathrm{g} / \mathrm{L}$. The serum also contained several phthalates which correlated with hormonal deficiencies related to reproductive tract development, and suggested that human Leydig cell development and function might be vulnerable to perinatal exposure to phthalates [40]. In rats phthalates interfere with the androgen signaling pathway. Specifically, exposure of pregnant rats to phthalates decreases mRNA ex- 
pression of key steroidogenic enzymes in fetal rat Leydig cells, ultimately lowering testosterone levels. Mixtures of phthalates with one another and other anti-androgenic compounds has a dose dependent additive effect that increases abnormal male reproductive tract development in rats [41] [42]. An epidemiologic study found that certain phthalates, including DEHP, measured in prenatal urine of pregnant women, correlated with reduced anogenital distance in human male infants of three years of age or less. This was the first evidence of developmental effects in male infants exposed prenatally to phthalates. Reduced anogenital distance in response to prenatal phthalate exposure has been well documented in rats as a phthalate syndrome [43] [44]. Estimates of daily exposure to DEHP in humans vary, with one study suggesting a median exposure of $1.32 \mu \mathrm{g} / \mathrm{kg} / \mathrm{day}$ and an exposure of $9.32 \mu \mathrm{g} / \mathrm{kg} / \mathrm{day}$ at the 95 th percentile [44], and another study suggesting a range from $3-30 \mu \mathrm{g} / \mathrm{kg} / \mathrm{day}$ [45]. High levels of phthalates can modulate the murine immune response to a coallergen. In addition, correlations have now been shown for indicators of home phthalate exposure and incidence of asthma and allergies [46]. Even adult males are affected by phthalate exposure, with higher phthalate levels measured in the urine of men with lower sperm counts and reduced sperm motility [47]. Phthalate exposure in humans has been hypothesized to cause a human analog of the phthalate syndrome in rats, where urinary metabolites in pregnant rats correlate with an increased risk of anti-androgenic activity in male rat pups [48]. A testicular dysgenesis syndrome in humans has also been hypothesized to occur with sufficient phthalate exposure. Symptoms include cryptorchidism and hypospadias in newborn males and low sperm counts and testicular germ cell cancer in young male adults [49].

Much of the early research with plastic additives like BPA or DEHP examined the effects on the development of the reproductive system. More recently the brain has been a target of BPA research. Specifically, BPA impaired spatial and passive avoidance memory in adult male mice, while reducing synaptic density and synaptic proteins in the hippocampus of adult and young male mice [50] [51]. In addition, BPA reduced spine synapses in the hippocampus of fetal monkeys but not juvenile monkeys [52]. Finally, BPA decreased motor behaviors and axonal growth of motor neurons in developing zebrafish [53]. We are unaware of any comparable studies with DEHP.

Very little research has examined the effects of BPA or DEHP on skeletal muscle development. Myotube formation and myogenin protein levels were decreased by DEHP in a study with C2C12 cells [54]. They reported that $1000 \mu \mathrm{g} / \mathrm{ml}$ DEHP increased the percentage of nuclei remaining as myoblasts by 1.84 fold, with more modest increases at lower concentrations of DEHP. This compares with our data that $100 \mu \mathrm{M}(39 \mu \mathrm{g} / \mathrm{ml})$ DEHP increased the percentage of nuclei in myoblasts 2.66 fold. They also reported that $1000 \mu \mathrm{g} / \mathrm{ml}$ DEHP decreased myogenin protein after three days in DM by about $25 \%$. This compares with our data that $100 \mu \mathrm{M}$ (39 $\mu \mathrm{g} / \mathrm{ml}$ ) DEHP decreased myogenin protein after three days in DM by about $50 \%$. Differences in experimental protocol account for the variability in data obtained, but the results are the same. DEHP decreases myotube formation and myogenin protein levels in C2C12 cell culture. We are unaware of any comparable study with BPA other than our own data that BPA also decreases myotube formation and myogenin protein levels. This may be a general effect of plastic additives on skeletal muscle development.

\section{Conclusion}

Since BPA and DEHP interfere with myotube formation and subsequent neuromuscular synapse formation, they may pose a risk for skeletal muscle development in humans. The results reported here demonstrate that $10 \mu \mathrm{M}$ BPA or $100 \mu \mathrm{M}$ DEHP decreased the frequency of agrin-induced AChR clusters and myotube formation. Furthermore, BPA or DEHP reduced the amount of myogenin protein. This suggests that BPA and DEHP decrease AChR clustering by reducing myogenin, and that myogenic regulatory factors like myogenin are intricately linked to the development of the postsynaptic component of the neuromuscular synapse.

\section{Acknowledgements}

This work was supported by the Office of Research and Sponsored Programs at Midwestern University through intramural funding for Wade A. Grow. A preliminary account of this work has appeared in abstract form [55].

\section{References}

[1] Fambrough, D.M. (1979) Control of Acetylcholine Receptors in Skeletal Muscle. Physiological Reviews, 59, $165-227$. 
[2] Fertuck, H.C. and Salpeter, M.M. (1976) Quantitation of Junctional and Extrajunctional Acetylcholine Receptors by Electron Microscope Autoradiography after 125I-Alpha-Bungarotoxin Binding at Mouse Neuromuscular Junctions. Journal of Cell Biology, 69, 144-158. http://dx.doi.org/10.1083/jcb.69.1.144

[3] Hall, Z.W. and Sanes, J.R. (1993) Synaptic Structure and Development: The Neuromuscular Junction. Cell, 72/10 (suppl.), 99-121.

[4] Bowe, M.A. and Fallon, J.R. (1995) The Role of Agrin in Synapse Formation. Annual Review of Neuroscience, 18, 443-462. http://dx.doi.org/10.1146/annurev.ne.18.030195.002303

[5] Zong, Y. and Jin, R. (2013) Structural Mechanisms of the Agrin-LRP4-MuSK Signaling Pathway in Neuromuscular Junction Differentiation. Cellular and Molecular Life Sciences, 70, 3077-3088. http://dx.doi.org/10.1007/s00018-012-1209-9

[6] Bowen, D.C., Park, J.S., Bodine, S., Stark, J.L., Valenzuela, D.M., Stitt, T.N., Yancopoulos, G.D., Lindsay, R.M., Glass, D.J. and DiStefano, P.S. (1998) Localization and Regulation of MuSK at the Neuromuscular Junction. Developmental Biology, 199, 309-319. http://dx.doi.org/10.1006/dbio.1998.8936

[7] Gautam, M., DeChiara, T.M., Glass, D.J., Yancopoulos, G.D. and Sanes, J.R. (1999) Distinct Phenotypes of Mutant Mice Lacking Agrin, MuSK, or Rapsyn. Brain Research. Developmental Brain Research, 114, 171-178. http://dx.doi.org/10.1016/S0165-3806(99)00013-9

[8] Glass, D.J., Bowen, D.C., Stitt, T.N., Radziejewski, C., Bruno, J., Ryan, T.E., Gies, D.R., Shah, S., Mattsson, K., Burden, S.J., DeStefano, P.S., Valenzuela, D.M., DeChiara, T.M. and Yancopolous, G.D. (1996) Agrin Acts via a MuSK Receptor Complex. Cell, 85, 513-523. http://dx.doi.org/10.1016/S0092-8674(00)81252-0

[9] Sugiyama, J.E., Glass, D.J., Yancopoulos, G.D. and Hall, Z.W. (1997) Laminin-Induced Acetylcholine Receptor Clustering: An Alternative Pathway. Journal of Cell Biology, 139, 181-191. http://dx.doi.org/10.1083/jcb.139.1.181

[10] Valenzuela, D.M., Stitt, T.N., DeStefano, P.S., Rojas, E., Mattsson, K., Compton, D.L., Nunez, L., Park, J.S., Stark, J.L., Gies, D.R., Thomas, S., LeBeau, M.M., Fernald, A.A., Copeland, N.G., Jenkins, N.A., Burden, S.J. and Yancopolous, G.D. (1995) Receptor Tyrosine Kinase Specific for the Skeletal Muscle Lineage: Expression in Embryonic Muscle, at the Neuromuscular Junction, and after Injury. Neuron, 15, 573-584. http://dx.doi.org/10.1016/0896-6273(95)90146-9

[11] Campanelli, J.T., Roberds, S.L., Campbell, K.P. and Scheller, R.H. (1994) A Role for Dystrophin-Associated Glycoproteins and Utrophin in Agrin-Induced AChR Clustering. Cell, 77, 663-674. http://dx.doi.org/10.1016/0092-8674(94)90051-5

[12] Sugiyama, J., Bowen, D.C. and Hall, Z.W. (1994) Dystroglycan Binds Nerve and Muscle Agrin. Neuron, 13, $103-115$. http://dx.doi.org/10.1016/0896-6273(94)90462-6

[13] Cohen, M.W., Jacobson, C., Godfrey, E.W., Campbell, K.P. and Carbonetto, S. (1995) Distribution of Alpha-Dystroglycan during Embryonic Nerve-Muscle Synaptogenesis. Journal of Cell Biology, 129, 1093-1101. http://dx.doi.org/10.1083/jcb.129.4.1093

[14] Fuhrer, C., Sugiyama, J.E., Taylor, R.G. and Hall, Z.W. (1997) Association of Muscle-Specific Kinase MuSK with the Acetylcholine Receptor in Mammalian Muscle. The EMBO Journal, 16, 4951-4960. http://dx.doi.org/10.1093/emboj/16.16.4951

[15] Grow, W.A. and Gordon, H. (2000) Acetylcholine Receptors Are Required for Postsynaptic Aggregation Driven by the Agrin Signaling Pathway. European Journal of Neuroscience, 12, 467-472. http://dx.doi.org/10.1046/j.1460-9568.2000.00923.x

[16] Yaffe, D. and Saxel, O. (1977) Serial Passaging and Differentiation of Myogenic Cells Isolated from Dystrophic Mouse Muscle. Nature, 270, 725-727. http://dx.doi.org/10.1038/270725a0

[17] Blau, H.M., Pavlath, G.K., Hardeman, E.C., Chiu, C.P., Silberstein, L., Webster, S.G., Miller, S.C. and Webster, C. (1985) Plasticity of the Differentiated State. Science, 230, 758-766. http://dx.doi.org/10.1126/science.2414846

[18] Godfrey, E.W., Nitkin, R.M., Wallace, B.G., Rubin, L.L. and McMahan, U.J. (1984) Components of Torpedo Electric Organ and Muscle that Cause Aggregation of Acetylcholine Receptors on Cultured Muscle Cells. Journal of Cell Biology, 99, 615-627. http://dx.doi.org/10.1083/jcb.99.2.615

[19] Nitkin, R.M., Smith, M.A., Magill, C., Fallon, J.R., Yao, Y.M., Wallace, B.G. and McMahan, U.J. (1987) Identification of Agrin, a Synaptic Organizing Protein from Torpedo Electric Organ. Journal of Cell Biology, 105, $2471-2478$. http://dx.doi.org/10.1083/jcb.105.6.2471

[20] McMahan, U.J. (1990) The Agrin Hypothesis. Cold Spring Harbor Symposia on Quantitative Biology, 55, 407-418. http://dx.doi.org/10.1101/SQB.1990.055.01.041

[21] Ferns, M.J., Campanelli, J.T., Hoch, W., Scheller, R.H. and Hall, Z. (1993) The Ability of Agrin to Cluster AChRs Depends on Alternative Splicing and on Cell Surface Proteoglycans. Neuron, 11, 491-502. http://dx.doi.org/10.1016/0896-6273(93)90153-I 
[22] Ferns, M., Deiner, M. and Hall, Z. (1996) Agrin-Induced Acetylcholine Receptor Clustering in Mammalian Muscle Requires Tyrosine Phosphorylation. Journal of Cell Biology, 132, 937-944. http://dx.doi.org/10.1083/jcb.132.5.937

[23] Wallace, B.G., Qu, Z. and Richard, H.L. (1991) Agrin Induces Phosphorylation of the Nicotinic Acetylcholine Receptor. Neuron, 6, 869-878. http://dx.doi.org/10.1016/0896-6273(91)90227-Q

[24] Tang, H., Sun, Z. and Goldman, D. (2001) CaM Kinase II-Dependent Suppression of Nicotinic Acetylcholine Receptor Delta-Subunit Promoter Activity. Journal of Biological Chemistry, 276, 26057-26065. http://dx.doi.org/10.1074/jbc.M101670200

[25] Tang, H., Macpherson, P., Argetsinger, L.S., Cieslak, D., Suhr, S.T., Carter-Su, C. and Goldman, D. (2004) CaM Kinase II-Dependent Phosphorylation of Myogenin Contributes to Activity-Dependent Suppression of nAChR Gene Expression in Developing Rat Myotubes. Cellular Signalling, 16, 551-563. http://dx.doi.org/10.1016/j.cellsig.2003.09.006

[26] Schapiro, M. (2007) Sex \& Plastic. In: Exposed: The Toxic Chemistry of Everyday Products and What's at Stake for American Power, Chelsea Green Publishing Company, White River Junction, 42-66.

[27] Steffens, B.W., Batia, L.M., Baarson, C.J., Choi, C.K.C. and Grow, W.A. (2007) The Pesticide Methoxychlor Decreases Myotube Formation in Cell Culture by Slowing Myoblast Proliferation. Toxicology in Vitro, 21, 770-781. http://dx.doi.org/10.1016/j.tiv.2007.01.007

[28] Grow, W.A. and Eroschenko, V.P. (2002) The Pesticide Methoxychlor Disrupts the Fusion of Myoblasts into Myotubes in Skeletal Muscle Cell Culture. Toxicology and Applied Pharmacology, 179, 105-110. http://dx.doi.org/10.1006/taap.2002.9355

[29] Ravdin, P. and Axelrod, D. (1977) Fluorescent Tetramethyl Rhodamine Derivatives of Alpha-Bungarotoxin: Preparation, Separation, and Characterization. Analytical Biochemistry, 80, 585-592. http://dx.doi.org/10.1016/0003-2697(77)90682-0

[30] Rando, T.A. and Blau, H.M. (1994) Primary Mouse Myoblast Purification, Characterization, and Transplantation for Cell-Mediated Gene Therapy. Journal of Cell Biology, 125, 1275-1287. http://dx.doi.org/10.1083/jcb.125.6.1275

[31] Miller, T.J. and Grow, W.A. (2004) Mercury Decreases the Frequency of Induced but Not Spontaneous Clustering of Acetylcholine Receptors. Cell and Tissue Research, 316, 211-219. http://dx.doi.org/10.1007/s00441-004-0878-6

[32] Owen, D.B., Chamberlain, K.T., Shishido, S. and Grow, W.A. (2010) Ethanol Decreases Agrin-Induced Acetylcholine Receptor Clustering in C2C12 Myotube Culture. Toxicology in Vitro, 24, 645-651. http://dx.doi.org/10.1016/j.tiv.2009.09.020

[33] Willhite, C.C., Ball, G.L. and McLellan, C.J. (2008) Derivation of a Bisphenol A Oral Reference Dose (RfD) and Drinking-Water Equivalent Concentration. Journal of Toxicology and Environmental Health Part B, 11, 69-146. http://dx.doi.org/10.1080/10937400701724303

[34] Olea, N., Pulgar, R., Perez, P., Olea-Serrano, F., Rivas, A., Novillo-Fertrell, A., Pedraza, V., Soto, A.M. and Sonnenschein, C. (1996) Estrogenicity of Resin-Based Composites and Sealants Used in Dentistry. Environmental Health Perspectives, 104, 298-305. http://dx.doi.org/10.1289/ehp.96104298

[35] Kamrin, M.A. (2004) Bisphenol A: A Scientific Evaluation. Medscape General Medicine, 6, 7.

[36] Miyamoto, K. and Kotake, M. (2006) Estimation of Daily Bisphenol A Intake of Japanese Individuals with Emphasis on Uncertainty and Variability. Environmental Sciences, 13, 15-29.

[37] Cao, X.L., Dufresne, G., Belisle, S., Clement, G., Falicki, M., Beraldin, F. and Rulibikiye, A. (2008) Levels of Bisphenol A in Canned Liquid Infant Formula Products in Canada and Dietary Intake Estimates. Journal of Agricultural and Food Chemistry, 56, 7919-7924. http://dx.doi.org/10.1021/jf8008712

[38] Kang, J.H., Kondo, F. and Katayama, Y. (2006) Human Exposure to Bisphenol A. Toxicology, 226, 79-89. http://dx.doi.org/10.1016/j.tox.2006.06.009

[39] Latini, G., De Felice, C., Presta, G., Del Vecchio, A., Paris, I., Ruggieri, F. and Mazzeo, P. (2003) In Utero Exposure to Di-(2-ethylhexyl)phthalate and Duration of Human Pregnancy. Environmental Health Perspectives, 111, 1783-1785. http://dx.doi.org/10.1289/ehp.6202

[40] Main, K.M., Mortensen, G.K., Kaleva, M.M., Boisen, K.A., Damgaard, I.N., Chellakooty, M., Schmidt, I.M., Suomi, A.M., Virtanen, H.E., Petersen, D.V., Andersson, A.M., Toppari, J. and Skakkebaek, N.E. (2006) Human Breast Milk Contamination with Phthalates and Alterations of Endogenous Reproductive Hormones in Infants Three Months of Age. Environmental Health Perspectives, 114, 270-276. http://dx.doi.org/10.1289/ehp.8075

[41] Wilson, V.S., Blystone, C.R., Hotchkiss, A.K., Rider, C.V. and Gray, L.E. (2008) Diverse Mechanisms of Anti-Androgen Action: Impact on Male Rat Reproductive Tract Development. International Journal of Andrology, 31, 178-187. http://dx.doi.org/10.1111/j.1365-2605.2007.00861.x

[42] Howdeshell, K.L., Rider, C.V., Wilson, V.S. and Gray, L.E. (2008) Mechanisms of Action of Phthalate Esters, Indivi- 
dually and in Combination, to Induce Abnormal Reproductive Development in Male Laboratory Rats. Environmental Research, 108, 168-176. http://dx.doi.org/10.1016/j.envres.2008.08.009

[43] Swan, S.H., Main, K.M., Liu, F., Stewart, S.L., Kruse, R.L., Calafat, A.M., Mao, C.S., Redmon, J.B., Ternand, C.L., Sullivan, S. and Teague, J.L. (2005) Decrease in Anogenital Distance among Male Infants with Prenatal Phthalate Exposure. Environmental Health Perspectives, 113, 1056-1061. http://dx.doi.org/10.1289/ehp.8100

[44] Marsee, K., Woodruff, T.J., Axelrad, D.A., Calafat, A.M. and Swan, S.H. (2006) Estimated Daily Phthalate Exposures in a Population of Mothers of Male Infants Exhibiting Reduced Anogenital Distance. Environmental Health Perspectives, 114, 805-809. http://dx.doi.org/10.1289/ehp.8663

[45] Doull, J., Cattley, R., Elcombe, C., Lake, B.G., Swenberg, J., Wilkinson, C., Van Williams, G. and Gernert, M. (1999) A Cancer Risk Assessment of Di(2-ethylhexyl)phthalate: Application of the New U.S. EPA Risk Assessment Guidelines. Regulatory Toxicology and Pharmacology, 29, 327-357. http://dx.doi.org/10.1006/rtph.1999.1296

[46] Jaakkola, J.J. and Knight, T.L. (2008) The Role of Exposure to Phthalates from Polyvinyl Chloride Products in the Development of Asthma and Allergies: A Systematic Review and Meta-Analysis. Environmental Health Perspectives, 116, 845-853. http://dx.doi.org/10.1289/ehp.10846

[47] Duty, S.M., Silva, M.J., Barr, D.B., Brock, J.W., Ryan, L., Chen, Z., Herrick, R.F., Christiani, D.C. and Hauser, R. (2003) Phthalate Exposure and Human Semen Parameters. Epidemiology, 14, 269-277. http://dx.doi.org/10.1097/01.EDE.0000059950.11836.16

[48] Swan, S.H. (2008) Environmental Phthalate Exposure in Relation to Reproductive Outcomes and Other Health Endpoints in Humans. Environmental Research, 108, 177-184. http://dx.doi.org/10.1016/j.envres.2008.08.007

[49] Sharpe, R.M. and Skakkebaek, N.E. (2008) Testicular Dysgenesis Syndrome: Mechanistic Insights and Potential New Downstream Effects. Fertility and Sterility, 89, e33-e38. http://dx.doi.org/10.1016/j.fertnstert.2007.12.026

[50] Xu, X., Liu, X., Zhang, Q., Zhang, G., Lu, Y., Ruan, Q., Dong, F. and Yang, Y. (2013) Sex-Specific Effects of Bisphenol-A on Memory and Synaptic Structural Modification in Hippocampus of Adult Mice. Hormones and Behavior, 63, 766-775. http://dx.doi.org/10.1016/j.yhbeh.2013.03.004

[51] Xu, X., Xie, L., Hong, X., Ruan, Q., Lu, H., Zhang, Q., Zhang, G. and Liu, X. (2013) Perinatal Exposure to BisphenolA Inhibits Synaptogenesis and Affects the Synaptic Morphological Development in Offspring Male Mice. Chemosphere, 91, 1073-1081. http://dx.doi.org/10.1016/j.chemosphere.2012.12.065

[52] Elsworth, J.D., Jentsch, J.D., Vandevoort, C.A., Roth, R.H., Redmond Jr., D.E. and Leranth, C. (2013) Prenatal Exposure to Bisphenol A Impacts Midbrain Dopamine Neurons and Hippocampal Spine Synapses in Non-Human Primates. NeuroToxicology, 35, 113-120. http://dx.doi.org/10.1016/j.neuro.2013.01.001

[53] Wang, X., Dong, Q., Chen, Y., Jiang, H., Xiao, Q., Wang, Y., Li, W., Bai, C., Huang, C. and Yang, D. (2013) Bisphenol A Affects Axonal Growth, Musculature and Motor Behavior in Developing Zebrafish. Aquatic Toxicology, 142-143, 104-113. http://dx.doi.org/10.1016/j.aquatox.2013.07.011

[54] Chen, S.S., Hung, H.T., Chen, T.J., Hung, H.S. and Wang, D.C. (2013) Di-(2-ethylhexyl)-Phthalate Reduces MyoD and Myogenin Expression and Inhibits Myogenic Differentiation in C2C12 Cells. Journal of Toxicological Sciences, 38, 783-791. http://dx.doi.org/10.2131/jts.38.783

[55] Neufeld, K.S. and Grow, W.A. (2011) Plastic Additives Decrease Myotube Formation and Agrin-Induced AChR Clustering in C2C12 Skeletal Muscle Cell Culture. American Osteopathic Association Conference, Orlando, 30 October 2011, 70. 